\title{
British Columbia experiments with checkups by the dozen
}

A lmost every Wednesday morning at 9:30, Geoff Bedford drops into his doctor's office in Fraser Lake, British Columbia - along with a dozen other patients - for a group checkup.

Everyone watches as Bedford's scores go up on a whiteboard: blood pressure, cholesterol, sugar, other test results. And when it's his turn to talk to the doctor, the other patients can listen in and ask questions.

Bedford, who is retired and has heart and kidney conditions, says he's comfortable sharing his private information. "If other people can learn from it, so much the better."

He's one of hundreds of patients in $\mathrm{BC}$ who are trying a new way of seeing their doctors - by group appointment. It's an innovative way of practising family medicine that has caught on with about 200 of the province's 4600 general practitioners.

In a typical group checkup, 12 to 15 patients share a 90-minute appointment with a doctor and nurse. They may have a common condition such as pregnancy, or chronic diseases such as diabetes, heart disease, hypertension, chronic pain and arthritis.

Group checkups are popular with patients and professionally satisfying for doctors, says the BC Medical Association, which has helped foster the practice in an effort to address a critical shortage of family physicians.

"I like it," says Dr. John Pawlovich, Bedford's physician at the Fraser Lake Community Health Centre. "It's just a fun way to practise medicine."

Since he started holding drop-in group visits in early 2007, Pawlovich says the waiting list in the 5-doctor clinic has been slashed and he has more time in his schedule for time-consuming appointments and outside specialty work. "For me, it's been a great change in my practice. I really look forward to Wednesday mornings."

Group medical visits were developed in Colorado in the early 1990s af-

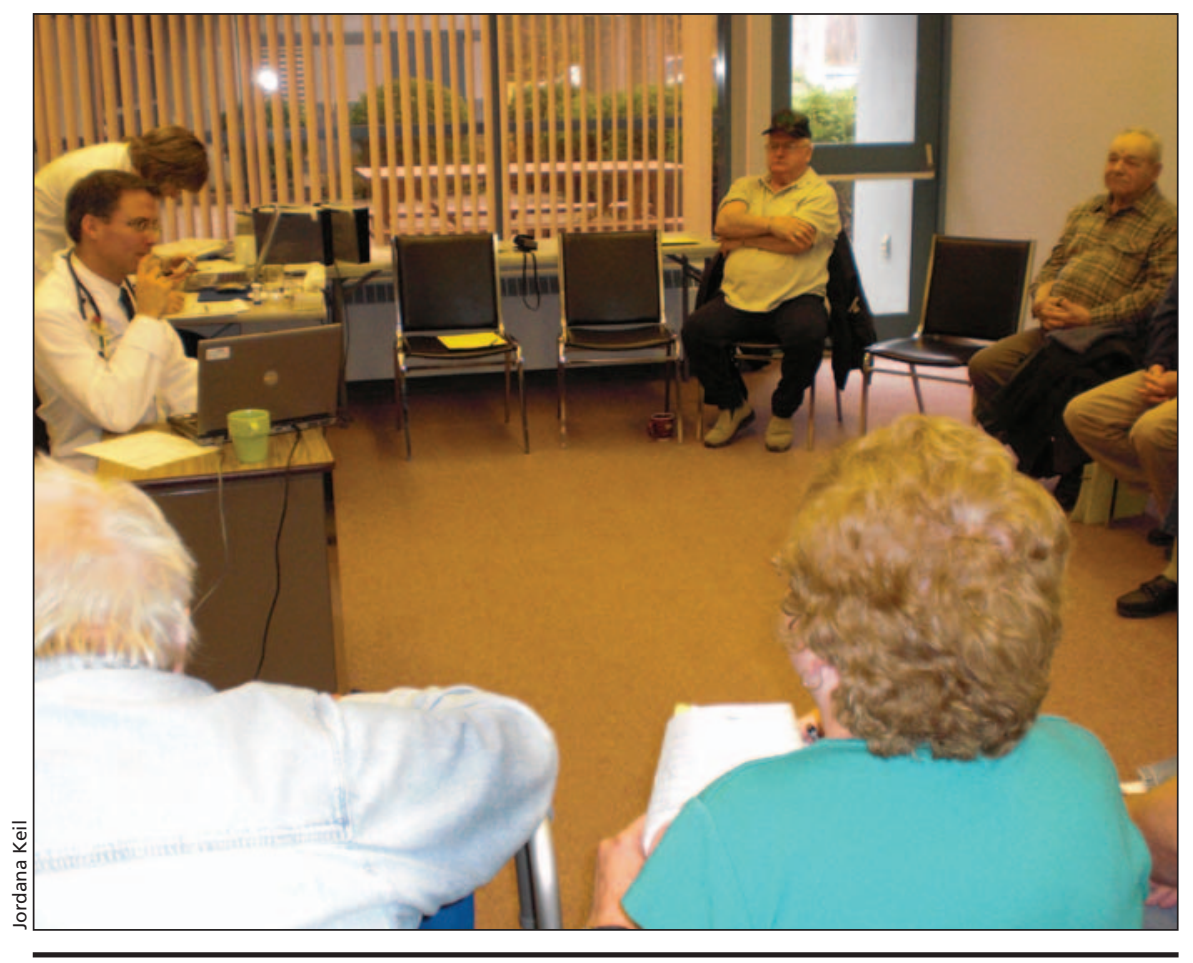

The British Columbia Medical Association is encouraging its physicians to see patients in groups. Doctors who have participated in group checkups say it is more efficient to deliver the same message to several patients simultaneously.

ter Dr. John Scott, a physician at a Kaiser Permanente Health Maintenance Organization, found he was delivering the same message numerous times a day to patients with the same chronic illnesses. He thought it would be more efficient and more supportive if similar patients were seen together during longer appointments.

Doctors in BC's northern health care region heard about the idea at an Institute for Healthcare Improvement conference in the United States, and by 2007 , the notion had attracted the attention of a joint committee struck by the BC Medical Association and the BC Ministry of Health to help improve family practices.

Doctors who have adopted group checkups now train other doctors and there's talk of the practice expanding to rheumatologists and orthopedic surgeons.

It's neither a money-maker for physicians nor a money-saver for governments, says Dr. Brian Brodie, a Chilliwack, BC, family physician and president-elect of the BC Medical Association. "At best, it's revenueneutral." Doctors bill their usual fee for each patient. To qualify for payment, the doctor must spend individual time with each patient, and the visit must be medically necessary, with assessment and treatment prescribed.

When it comes to privacy, doctors say most patients, like Bedford, are not overly concerned. Each patient signs a confidentiality agreement and anyone can see a physician alone at any time. No one is forced to attend group checkups.

BC's privacy watchdog sees no problem with the practice as long as patients are notified that they'll be in a group setting, participation is voluntary, and they give written consent that they won't divulge confidential infor- 
mation. If these conditions are met, says BC's Information and Privacy Commissioner David Loukidelis, "I'm very supportive of the idea, because I think the privacy issues can be well managed."

There's a paucity of literature on whether group checkups cause harm but studies indicate they could improve health status and reduce trips to emergency departments.

The BC Medical Association says it's too early to draw conclusions about whether group appointments improve participants' ability to manage their chronic conditions in the long term. But patients report that they learn more during group checkups than during regular office visits, and benefit from the support of others with similar health problems.

Debbie Dallas, a patient in Mackenzie, BC, 2 hours north of Prince George, BC, says group checkups for diabetics "are by far the best doctor's appointments that I have ever been to."

In an open letter posted on a website (www.impactbc.ca) with testimonials from doctors and patients, Dallas says she learns a lot from sharing problems and solutions with other patients.

She believes group sessions help everyone feel less alone and more confident their disease is treatable.

Bedford, 64, says the Wednesday checkups help him monitor his health regularly and stay on top of his problems with diet and lifestyle.

"It's a very positive experience," he says. "You learn a lot and you feel better at the end of the day."

In Chilliwack, BC, Brodie is just starting to offer middle-aged patients group checkups for cardiovascular health. Each patient's height, weight, blood pressure, body-mass index, Framingham score, cholesterol and fasting sugars will be measured and posted, along with a calculation showing their chance of having a heart attack in the next 4 years.

Group checkups are "a great thing for doctors to try," Brodie says. "This is something that's not going to go away." - Christie McLaren, Canmore, Alta.

DOI:10.1503/cmaj.081667

\section{Canada Health Act breaches are being ignored, pro-medicare groups charge}

$\mathrm{P}$ rivate for-profit medical clinics are proliferating across the country, according to a detailed report by pro-medicare groups.

The number of such clinics has increased significantly over the past 5 years and there's evidence "to suspect that 89 for-profit clinics in 5 provinces appear to be in breach of the Canada Health Act," states the 169-page Eroding Public Medicare: Lessons and Consequences of For-Profit Health Care Across Canada report.

But federal and provincial officials "have fallen down in their responsibility to protect patients against extra billing and 2-tier care," says report author Natalie Mehra, director of the Ontario Health Coalition.

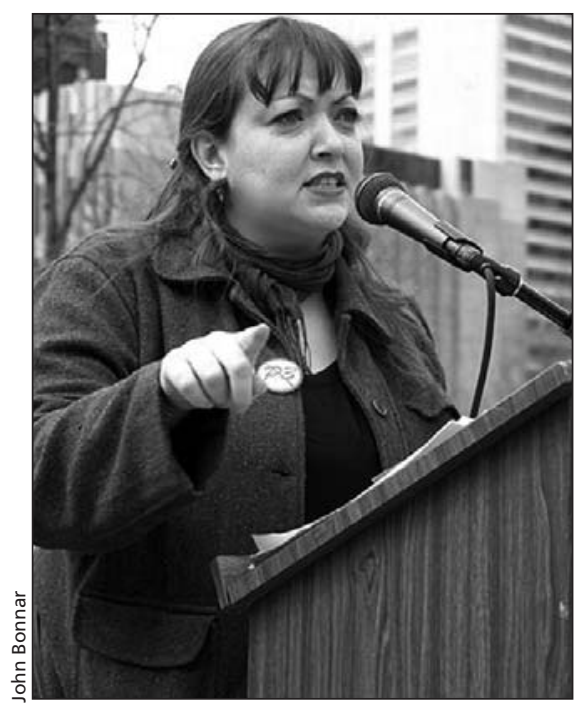

Canada is experiencing a boom in private for-profit clinics, says report author Natalie Mehra.

A spokesperson for federal Health Minister Tony Clement argued that enforcement of the Act falls to the provinces. "It is the responsibility of the provinces to ensure that providers of insured health services operate in compliance with the requirements of the Canada Health Act," said press secretary Laryssa Waler.

Lack of political will seems to explain the fact that the Act - which forbids extra billing for medically neces- sary care and requires that such care be provided to Canadians on uniform terms and conditions - is not being enforced, Mehra says.

"Certainly, it is not very difficult to establish what is going on," she adds, noting that researchers called up clinics and asked basic questions.

The report provides details on private clinics that offer magnetic resonance imaging (MRI) and computed tomography scans, surgical procedures, laser eye and cataract surgery. It also examines services offered by comprehensive "boutique" medical clinics that cater to wealthy clients.

Researchers also found evidence of physicians practising in hospitals but referring patients to their private forprofit businesses, where medically necessary services would be provided more quickly, for an out-of-pocket fee.

Former federal Health Minister Ujjal Dosanjh addressed the trend of doctors practising on both a publicly insured and private basis in a 2005 "Canadian Public Health Care Protection Initiative" statement, in which the government vowed to take action against the practice "when it undermines access to publicly insured services." But report researchers found no evidence of any enforcement.

In 1995, then-federal health minister Diane Marleau issued a policy interpretation letter calling on provinces to introduce "regulatory frameworks" to govern the operation of private clinics, and make illegal the "facility fees" charged by private clinics which provide publicly-insured services.

But report researchers found many examples of facility charges, including a \$240 fee charged to patients having publicly-paid-for colonoscopies at a Vancouver clinic, and a $\$ 450$ direct charge to patients having the same procedure in Montreal.

The report, was supported by several provincial health coalitions, the Council of Canadians, Canadian Doctors for Medicare and the Medical Reform Group. It concludes that increased numbers of private clinics allow for queue 